\title{
A INDÚSTRIA CULTURAL E O CYBERBULLYING CONTRA PROFESSORES: as agressões online à profissão de ensinar no contexto das tecnologias digitais
}

\author{
Camila Sandim de Castro \\ Escola Municipal "Professora Clotilde Rocha" \\ Antonio Álvaro Soares Zuin \\ Universidade Federal de São Carlos
}

\begin{abstract}
Resumo
A temática da violência escolar adquire novos contornos diante da disseminação das tecnologias digitais, sobretudo pelo modo como as práticas de cyberbullying se tornam cada vez mais presentes. Diante desse contexto, tem-se, como objetivo, refletir criticamente sobre as práticas de violência online cometidas contra professores, por meio da análise de um vídeo postado no YouTube, no qual um aluno agride uma professora. Considera-se que este fenômeno de cyberbullying precisa ser compreendido por meio do modo como a indústria cultural se revitaliza no contexto das denominadas tecnologias digitais. Conclui-se que as práticas de cyberbullying de alunos contra professores, as quais são viabilizadas pelos produtos da indústria cultural contemporânea, precisam ser objeto de atenção nas instituições de ensino para que a educação não reitere a barbárie nos tempos da cultura digital.
\end{abstract}

Palavras-chaves: Indústria Cultural; Agressões virtuais; Relação pedagógica.

\begin{abstract}
The theme of school violence acquires new contours with the spread of digital technologies, especially due to the way in which cyberbullying practices become more and more present. Given this context, the objective is to critically reflect on the online violence practices committed against teachers, through the analysis of a video posted on YouTube, in which a student attacks a teacher. It is considered that this phenomenon of cyberbullying needs to be understood through the way the cultural industry is revitalized in the context of so-called digital technologies. It is concluded that the cyberbullying practices of students against teachers, which are made possible by the products of the contemporary cultural industry, need to become the object of attention in educational institutions so that education does not reiterate barbarism in times of digital culture.
\end{abstract}

Key-words: Cultural Industry; Virtual aggressions; Pedagogical relationship. 


\section{Introdução}

O termo indústria cultural, cunhado por Horkheimer e Adorno (1985) na década de 1940, e já tão pesquisado e debatido em diferentes áreas do conhecimento, continua sendo um conceito fundamental para a compreensão de diversos fenômenos da vida social. Isso porque a indústria cultural acompanha as mudanças ocorridas na organização e nas relações de trabalho, consumo e modo de vida capitalista. Assim, graças ao desenvolvimento da robótica, da informática e da microeletrônica no contexto do processo produtivo capitalista neoliberal, a indústria cultural tem se revitalizado e mantido sua capacidade de, conforme os frankfurtianos, disseminar mercadorias que não cessam de prometer a realização dos desejos individuais sempre padronizados. Desse modo, a indústria cultural continua atuando na manutenção da ordem vigente e sempre que o status quo pareça ameaçado suas mercadorias buscam reconstruí-lo (ADORNO, 1978).

No contexto dos processos sociais educativos, observa-se que a produção e a reprodução das tecnologias digitais têm contribuído tanto para a construção do pensamento autônomo e criativo, haja vista a potencialidade formativa que tais tecnologias podem oferecer para a formação de professores e alunos, quanto para atualizar a violência escolar na relação pedagógica. As mesmas tecnologias inseridas nos espaços escolares utilizadas nos processos de ensino e aprendizagem também estão sendo usadas para a prática de agressões de alunos contra professores. São cada vez mais crescentes os casos da prática de cyberbullying em que os alunos filmam seus professores sendo agredidos em sala de aula e postam essas filmagens, acrescidas de comentários, nas chamadas redes sociais. Os conhecidos casos de bullying escolar são, no contexto da audiovisibilidade total, para usar uma expressão de Türcke (2010), reconfigurados sob a forma das agressões virtuais que tendem a ser ainda mais cruéis, pois as imagens e os comentários agressivos e humilhantes se disseminam velozmente no ciberespaço.

Considerando-se a relevância do conceito de indústria cultural para se investigar as atuais formas de violência escolar, tem-se, como objetivo, refletir criticamente sobre as práticas de violência online cometidas contra professores, por meio da análise de um video postado no YouTube, no qual um aluno agride uma professora. Parte-se do pressuposto de que este fenômeno de cyberbullying precisa ser compreendido através do modo como a indústria cultural se revitaliza no contexto das denominadas tecnologias digitais. Para tanto, na primeira seção apresentam-se os conceitos de bullying e cyberbullying com o intuito de explicitar as principais características desses fenômenos que se entrelaçam no contexto das práticas virtuais agressivas. Na segunda seção, além de tratar sobre a relação pedagógica e a autoridade docente, analisa-se um vídeo postado no YouTube que mostra uma professora sendo agredida por um estudante do ensino fundamental brasileiro. A análise desse vídeo busca tanto elucidar o fenômeno cyberbulllying contra professores quanto chamar a atenção para a necessidade ainda vigente de se educar contra a barbárie como defendeu Adorno (1995). A educação contra a barbárie, que passa necessariamente pela formação cultural mediada pelo exercício da autoridade docente, é responsável pelo desenvolvimento da sensibilidade e do comportamento ético nas relações sociais. 


\section{A violência escolar e o (cyber)bullying}

A temática da violência escolar é extensa e abarca diferentes objetivos, metodologias e referenciais teóricos para discutir, problematizar, analisar e compreender esse fenômeno. Os termos violência $d a$ escola, violência $n a$ escola e violência à escola cunhados por Charlot (2002) são comumente utilizados para compreender três tipos de violência escolar. No primeiro caso, a violência é institucional e está relacionada ao modo como os estudantes são tratados pelas instituições de ensino e seus agentes, tais como, "[...] modos de composição das classes, de atribuição de notas, de orientação, palavras desdenhosas dos adultos, atos considerados pelos alunos como injustos ou racistas" (p. 435). A violência da escola foi objeto de análise do pensador francês Michel Foucault (2010) ao tratar a escola como instituição que controla e vigia os tempos e os espaços escolares produzindo corpos dóceis e obedientes; é a chamada violência simbólica, nos termos dos pensadores, também franceses, Pierre Bourdieu e Jean-Claude Passeron (1992). Já a violência na escola, segundo Charlot, "[...] se produz dentro do espaço escolar, sem estar ligada à natureza e às atividades da instituição escolar [...]; a escola é apenas o lugar de uma violência que poderia ter acontecido em qualquer outro local" (p. 434). Por fim, a violência à escola está relacionada "[...] à natureza e às atividades da instituição escolar: quando os alunos provocam incêndios, batem nos professores ou os insultam, eles se entregam a violências que visam diretamente a instituição e aqueles que a representam" (p. 434).

Uma das expressões mais conhecidas da violência escolar são as agressões interpessoais que, sob a designação de bullying, se caracterizam pela intencionalidade e repetição em uma relação desigual de força entre os envolvidos. Esse tipo de violência foi primeiramente estudado pelo pesquisador norueguês Dan Olweus na década de 1970 por ocasião de suas pesquisas sobre a violência entre estudantes na região da Escandinávia. Para o autor, o termo bullying designa um comportamento agressivo direcionado contra uma pessoa por um indivíduo ou grupo de indivíduos numa relação em que há desequilíbrio de poder entre os envolvidos e repetição das agressões (OLWEUS, 1993).

Sobre as definições de violência escolar, Stelko-Pereira e Williams (2010, p. 46) destacam a "[...] dificuldade em se adotar uma única definição do que seja violência escolar. Uma dessas dificuldades consiste no fato de que a violência pode se expressar de múltiplas formas e ser compreendida de maneiras diversas". Para as autoras, o que comumente se entende por violência está relacionado a aspectos culturais, históricos e individuais; assim, “[...] é impossível uma única e verdadeira definição que seja aceita universalmente" (p. 47). No caso da conceituação de bullying, por exemplo, as pesquisadoras asseveram que "[...] não se pode dizer que exista bullying do professor para com o aluno, ou do pai para com o filho, pois se trata de uma situação de violência que ocorre entre pares” (p. 52). Esta definição não é consensual entre os pesquisadores envolvidos com a temática do conceito de bullying, já que muitos entendem que esse conceito não se limita a agressões ocorridas apenas entre pares, mas que se estendem, 
inclusive, para os casos de violência praticados por professores contra alunos (ANTUNES, 2010; CANAVEZ, 2015; SANTOS, 2001). Já em relação ao ambiente virtual, os professores também reagem violentamente a comentários agressivos que são postados por alunos logo abaixo dos vídeos do YouTube. Muito provavelmente pela sensação de distância possibilitada pela presença da tela, os alunos se sentem de tal forma empoderados que, em muitas ocasiões, não se preocupam com as reprimendas que poderiam sofrer diante da exposição das agressões online quanto a seus professores. De todo modo, quaisquer agressões tendem a permanecer para sempre nas redes sociais, mesmo que se adquira o direito na justiça de que sejam deletadas (ZUIN, 2017). Exatamente essa característica do conceito de cyberbullying precisa ser enfatizada, principalmente quando as práticas de agressões online, na forma de imagens e comentários humilhantes, são comparadas com as violências físicas e verbais cometidas presencialmente e que são associadas ao conceito de bullying. Com efeito, se a repetição prolongada das agressões verbais e físicas constitui "o coração do processo de bullying" (KYRIACOU, 2003, p.17), já em relação às práticas de cyberbullying observa-se que, justamente pelo fato das imagens e comentários humilhantes poderem ser postados e repostados ad infinitum, basta que ambos sejam publicados uma única vez. Frente a esse quadro, há pesquisadores que vinculam a consciência da vítima de cyberbullying, sobre a continuidade ininterrupta das agressões online que sofreu, com práticas de suicídio (HINDUJA; PATCHIN, 2010; O’HIGGINS; CONNOLY, 2011; BAUMAN; TOOMEY; WALKER, 2013).

Com a finalidade de apresentar os conceitos de bullying e cyberbullying, inclusive para contribuir com o debate acadêmico sobre as atuais definições desses termos, serão analisados, a seguir, textos e pesquisadores que se debruçam sobre tais definições. $\mathrm{O}$ conjunto de textos, artigos e livros apresentados sobre os conceitos de bullying e cyberbullying foi selecionado utilizando-se dois critérios, quais sejam: a) pesquisadores e pesquisadoras conhecidos (inter)nacionalmente que possuem vasta publicação sobre a temática; b) discussão abrangente sobre os conceitos de bullying e cyberbullying compreendendo visões críticas a respeito desses fenômenos.

Seguindo essa linha de raciocínio, Silva (2010, p. 21) define o termo bullying como um conjunto de "[...] atitudes de violência física e/ou psicológica, de caráter intencional e repetitivo, praticado por um bully (agressor) contra uma ou mais vítimas que se encontram impossibilitadas de se defender". Conforme a autora, o bullying pode acontecer de diferentes formas, a saber: a) verbal (insultos, ofensas, xingamentos, gozações); b) físico e material (espancamentos, socos e pontapés, empurrões, beliscões, furtos, destruição de objetos); c) psicológica e moral (humilhar, excluir, isolar, desprezar, intimidar, discriminar, perseguir, difamar); d) sexual (abusar, violentar, insinuar, assediar); e) virtual (cyberbullying).

Já para Smith (2002), o bullying é compreendido como sinônimo de intimidação podendo acontecer em diferentes ambientes e contextos como o local de trabalho, nas relações familiares, nas forças armadas, nas prisões, dentre outros. No caso das escolas, "é possível pensar em termos de intimidação de professor-a-professor, de professor-a-aluno, de aluno-a-professor, tanto quanto de aluno-a-aluno" (p. 188). 
Sobre o conceito de bullying, Tognetta e Rosário (2013, p. 108) afirmam que "se concordarmos que o ato de menosprezar, diminuir ou agredir, como um substrato de violência, é uma forma de desrespeito, podemos dizer que o bullying é um problema moral". Em pesquisa realizada com o objetivo de verificar se existe relação entre a "[...] participação em situações de bullying, as representações de si e como se autorregulam para compreender um conteúdo moral em jogo, desengajando-se ou engajando-se moralmente" (p. 116), os autores investigaram 2.600 adolescentes do $9^{\circ}$ ano do Ensino Fundamental, com idade média de 15 anos, de escolas públicas e privadas do Estado de São Paulo. Os dados da pesquisa mostraram que

os alvos de bullying se apresentam tanto engajados como desengajados moralmente, o que não acontece quando correlacionamos os autores de bullying aos desengajamentos morais. Eles são mais desengajados e menos engajados nas situações morais. Isso denota, novamente, que a vitimização é um problema moral. Meninos e meninas que são autores de bullying demonstram desativar mais seletivamente o controle de um mau comportamento moral e reconstroem assim o significado dessa conduta reprovável, justificando-a moralmente (TOGNETTA; ROSÁRIO, 2013, p. 130).

A compreensão do bullying como um problema moral é subsidiada pela teoria do desengajamento moral desenvolvida por Albert Bandura. Este autor esclarece que a justificativa moral, a linguagem eufemística e a comparação vantajosa formam o conjunto mais eficaz de mecanismos psicológicos utilizados para promover o desengajamento do controle moral. Para o pesquisador, "investir altos propósitos morais na conduta danosa não elimina apenas a autocensura, mas promove a autoaprovação a serviço de explorações destrutivas. O que foi uma vez moralmente condenável torna-se uma fonte de autoavaliação positiva" (BANDURA, 2015, p. 29). Por justificativa moral, o autor explica que

as pessoas não se engajam comumente em condutas prejudiciais até que elas tenham justificado para si mesmas a moralidade de suas ações. Neste processo de justificativa moral, a conduta prejudicial é transformada em pessoal e moralmente aceitável ao retratá-la como sendo socialmente válida ou com propósitos morais (BANDURA, 2015, p. 23).

De acordo com o pesquisador, além de justificar para si mesmo que a ação prejudicial praticada não é imoral, é comum utilizar-se da linguagem eufemística que opera no sentido de fazer com que o comportamento nocivo seja transformado em respeitável isentando-se da própria responsabilidade por tal comportamento. Segundo Bandura (2015, p. 25), "as pessoas comportam-se de forma muito mais cruel quando as ações agressivas são verbalmente saneadas do que quando são chamadas de agressão".

Já no caso da comparação vantajosa utiliza-se a exploração do princípio de contraste de modo que "[...] os atos repreensíveis possam parecer justos" (BANDURA, 2015, p. 27). Assim, 
quanto mais evidente a desumanidade contrastada, maior a probabilidade que a conduta destrutiva de alguém pareça benevolente. Por exemplo, a enorme destruição no Vietnam foi minimizada ao retratar a intervenção militar americana como uma salvação da população da escravização comunista (BANDURA, 2015, p. 27).

No entendimento de Tognetta e Rosário (2013), o exercício do controle moral é enfraquecido nas situações em que as relações interpessoais são caracterizadas por agressões recorrentes e intencionais como nos casos de bullying entre alunos. De fato, as agressões intencionais e repetidas assinaladas pela desigualdade de poder entre agressor e vítima que caracterizam o bullying se relacionam tanto com a liberação da conduta moral quanto com a dificuldade de se sensibilizar diante do sofrimento do outro. Ao discutir a necessidade de uma educação que não reproduza Auschwitz, logo, de uma educação que seja capaz de promover a desbarbarização social, Adorno (1995) esclareceu que quem é insensível consigo mesmo toma-se no direito de ser insensível com os outros também. Tal comportamento pode ser entendido, segundo o pensador, como uma forma de lidar com a própria dor que precisou ser ocultada e/ou reprimida.

Em função do número expressivo dos casos de bullying assim como dos prejuízos formativos e socioemocionais para as vítimas, para os agressores e também para os espectadores, em 06 de novembro de 2015, foi sancionada a Lei n. 13.185 que instituiu o Programa de Combate à Intimidação Sistemática nas escolas brasileiras. Dentre os objetivos do Programa estão o combate e a prevenção dos casos de bullying; a capacitação docente para implementar ações que promovam o debate, a prevenção, a orientação e a solução do problema; o apoio psicológico, social e jurídico às vítimas e aos agressores e a promoção da cidadania e do respeito aos outros.

O Programa de Combate à Intimidação Sistemática (Lei n. 13.185/2015) também tem como objeto de prevenção e combate o chamado cyberbullying sendo definido como intimidação sistemática que acontece no ciberespaço "[...] quando se usam os instrumentos que lhe são próprios para depreciar, incitar a violência, adulterar fotos e dados pessoais com o intuito de criar meios de constrangimento psicossocial" (BRASIL, 2015). Para Silva (2010, p. 126), o cyberbullying pode ser definido como bullying virtual, já que os agressores utilizam "[...] os mais atuais e modernos instrumentos da internet e de outros avanços tecnológicos na área da informação e da comunicação com o covarde intuito de constranger, humilhar e maltratar suas vítimas". Enquanto o bullying está relacionado a agressões em que existe o contato entre vítima e agressor, o cyberbullying se caracteriza por agressões e humilhações direcionadas contra o outro em ambientes virtuais. Nesse tipo de violência as agressões tendem a ser ainda mais cruéis, pois as humilhações sofridas podem ser compartilhadas no ciberespaço, especialmente nas redes sociais. Conforme Almeida (2012, p. 77), 
diferentemente do bullying tradicional, que normalmente se restringe ao espaço escolar, esta nova modalidade de agressão e intimidação revela-se como um tipo de violência mais cruel, uma vez que extrapola os ambientes escolares e as vítimas sofrem humilhações e ameaças constantes por meio de mensagens de celular, e-mails, postagens em redes sociais, dentre outras.

Sendo assim, a prática de cyberbullying é muitas vezes realizada com a publicação de vídeos e comentários pela criação de perfis falsos nas redes sociais como forma de se proteger das possíveis punições por meio do suposto anonimato oferecido pelas telas dos aparelhos tecnológicos. A criação desses perfis assim como o compartilhamento das imagens agressivas nas redes sociais contribui para que o cyberbullying envolva um número ainda maior de vítimas e espectadores quando comparado ao bullying "[...] devido à velocidade de propagação de informações nos meios virtuais" (TOGNETTA; BOZZA, 2010, p. 842).

Além do potencial multiplicativo das mensagens e imagens humilhantes característico da prática de cyberbullying, Rocha (2010) destaca o fato de o conteúdo dessas mensagens e imagens ficar armazenado no ciberespaço, a possibilidade de anonimato oferecido pela internet como elemento encorajador para que as agressões aconteçam e a presença dos espectadores. Sobre estes, a autora explica que o "[...] cyberbullying depende da existência dos espectadores. A divulgação massificada de imagens, informações privadas ou perturbadoras funciona na medida em que estas são vistas" (p. 127). Dessa maneira, os espectadores podem: a) denunciar as mensagens e as imagens humilhantes; b) compartilhálas e/ou comentá-las; c) apenas visualizá-las, sem tomar nenhuma decisão que cesse a agressão ou que dê continuidade a ela (ROCHA, 2010). A presença de espectadores contribui para agravar o sofrimento das vítimas de cyberbullying haja vista as consequências psíquicas e emocionais sofridas por elas, pois, para Prados e Fernández (2007), nesse tipo de violência, o agressor ao não ter contato com a vítima também não tem empatia por sua dor.

Conte e Rossini (2010) apresentam seis modalidades de cyberbullying, quais sejam: 1) Flaming, conhecido como provocação online, que "consiste no envio de mensagens vulgares ou que mostram hostilidade em relação a uma pessoa. [...] As mensagens são chamadas de flames (chamas), pois visam provocar a vítima” (p. 54). 2) Cyberstalking, ou perseguição online, é uma forma de violência sutil “[...] perceptível somente pela própria pessoa a que se dirige, visando atacá-la psicologicamente através de repetidas mensagens de aproximação via e-mails, scraps, postagens em blogs, etc.” (p. 54). 3) Substituição da pessoa, ou perfil fake, "trata-se da conduta daquele que se faz passar pela vítima, enviando mensagens ou postando arquivos de texto, vídeo ou imagem que difamem o agredido" (p. 55). 4) Outing, é a disseminação de "[...] informações ou características pessoais relacionadas a opções políticas, religiosas, sexuais ou qualquer outro tipo de informação que a vítima deseja que permaneça em sigilo" (p. 55-56). 5) Exclusão, conhecida como apartheid digital, "é a expulsão de alguém de grupo ou comunidade on-line" (p. 56). 6) 
Sexting, prática violenta que "consiste em espalhar eletronicamente material de conteúdo sexual" (p. 56).

Em relação às punições legais para a prática de cyberbullying, Conte e Rossini (2010) asseveram que por não existir uma lei específica para os casos de agressões virtuais tem-se aplicado as regras discriminadas no Código Civil, no Código Penal e no Estatuto da Criança e do Adolescente. Como destaca os autores, alguns desses casos podem ser amoldados a situações já existentes na legislação brasileira, como: "crimes contra a honra (arts. 138 - 140 do Código Penal), crime de constrangimento ilegal (art. 146 do Código Penal), crime de ameaça (art. 147 do Código Penal), crime de participação em suicídio (art. 122 do Código Penal), pornografia infantil" (p. 62). Em 2012, foi sancionada a Lei n. 12.737, que dispõe sobre a tipificação criminal de delitos informáticos considerando criminoso quem, conforme artigo 154-A,

invadir dispositivo informático alheio, conectado ou não à rede de computadores, mediante violação indevida de mecanismo de segurança e com o fim de obter, adulterar ou destruir dados ou informações sem autorização expressa ou tácita do titular do dispositivo ou instalar vulnerabilidades para obter vantagem ilícita (BRASIL, 2012).

Ainda não há na legislação brasileira, como observado pelos autores, uma lei específica para punir os casos de cyberbullying. Apesar de a Lei n. 13.185/2015, que institui o Programa de Combate à Intimidação Sistemática, representar um avanço em termos de legislação ela dispõe apenas sobre a prevenção, o diagnóstico e o combate ao bullying e ao cyberbullying. Dessa forma, a punição aos agressores e a reparação dos danos causados às vítimas ainda não discriminadas em lei específica contribui para a continuidade e o aumento dos casos de bullying e cyberbullying, já que o sentimento de não ser responsabilizado criminalmente pode incentivar a prática de tais atos agressivos.

\section{A relação pedagógica e o cyberbullying de alunos contra professores}

A figura do professor sempre despertou interesse nos alunos. Freud (1969), num texto da década de 1930, revelou o modo como o professor sempre fora objeto da projeção de sentimentos de ambivalência (amor e ódio) por parte dos alunos. O psicanalista asseverou que a personalidade dos mestres despertava tanto a atenção dos alunos, quanto os conteúdos disciplinares ensinados por eles:

nós os cortejávamos ou lhes virávamos as costas; imaginávamos neles simpatias e antipatias que provavelmente não existiam; estudávamos seus caráteres e sobre estes formávamos ou deformávamos os nossos. Eles provocavam nossa mais enérgica oposição e forçavam-nos a uma submissão completa; bisbilhotávamos suas pequenas fraquezas e orgulhávamo-nos de sua excelência, seu conhecimento e sua justiça. [...] Estávamos, desde o princípio, igualmente 
inclinados a amá-los ou odiá-los, a criticá-los e a respeitá-los (FREUD, 1969, p. 286).

O professor foi entendido por Freud (1969, p. 287) como um ideal de eu, como um “[...] modelo não apenas a ser imitado, mas também a ser eliminado para que possamos tomar o seu lugar". Ou seja, o professor é tomado como exemplo, como referência para que os valores morais e o comportamento ético possam ser internalizados de modo que o aluno se transforme em um adulto. Nesse processo, o professor precisa ser superado (Aufhebung), isto é, o aluno ao mesmo tempo que deve conservar dentro de si a figura do professor precisa transformá-la para conseguir se apropriar dos conteúdos disciplinares e pensar por si mesmo. Por isso, os alunos projetam na imagem de seus mestres sentimentos de amor e ódio, expectativas, desejos (sexuais ou não) e frustrações. Dessa forma, tal como afirmou Freud (1969), apesar de muitos professores ainda serem jovens, os alunos se sentem impressionados com sua maturidade justamente porque representam protótipos daquilo que eles almejam ser quando adultos.

O processo de construção da autonomia e da identidade pela qual os alunos precisam passar para se tornarem adultos e sujeitos de seu próprio pensamento depende do exercício da autoridade docente. É o professor enquanto autoridade pedagógica que fará a mediação entre o conhecimento transmitido e o processo de aprendizagem do aluno. De acordo com Zuin (2008, p. 112),

[...] se o modelo, no caso o professor, é um elemento relevante para a formação da identidade do aluno que se sente instigado a superá-lo, o próprio mestre precisa deixar de aferrar-se ao gosto de sentir-se o centro das atenções e perceber que, ao ensinar, uma parte de si morre para que possa renascer mediada na intervenção do aluno.

A autoridade docente é imprescindível para o crescimento intelectual do aluno, já que a superação dialética do mestre exige que o aprendiz se identifique com ele. A importância da autoridade docente que perpassa o processo de identificação com o professor de modo a superá-lo pode ser resumida no ensinamento de Zaratustra ao afirmar que "retribui-se mal um mestre quando se permanece sempre e somente discípulo. E por que não quereis arrancar as folhas de minha coroa?" (NIETZSCHE, 2005, p. 105). Assim, o exercício da autoridade docente cônscio de seus limites instiga a sua superação que "[...] não significa sua eliminação, uma vez que a intervenção do educador conserva-se modificada no raciocínio elaborado pelo aluno, que se sente respeitado como partícipe do processo de ensino-aprendizagem" (ZUIN, 2008, p. 37).

A relação respeitosa entre professores e alunos em sala de aula, estabelecida pelo exercício da autoridade docente e que permite o processo de superação acima descrito, temse enfraquecido na atualidade, haja vista o crescente número de agressões contra professores tanto no espaço físico das instituições de ensino quanto nos ambientes virtuais. A violência contra professores, especialmente no formato de cyberbullying, recrudesce num 
contexto em que há um deslocamento do exercício da autoridade docente para as atuais tecnologias digitais da indústria cultural. Assim, são essas tecnologias que têm cada vez mais ocupado o lugar de ideal de eu dos alunos afastando-os da possibilidade de construírem uma relação respeitosa com seus professores. De fato, há vídeos disponíveis no YouTube nos quais professores de escolas de vários países retiram à força os aparelhos celulares das mãos dos alunos e os espatifam no chão da sala de aula. A procederem dessa forma, os professores procuram recuperar agressivamente a atenção dos alunos nos conteúdos de suas respectivas matérias, nem que seja por meio do uso da força física. Dessa maneira, o declínio da autoridade docente em que os aparatos tecnológicos seduzem os alunos de um modo que os professores não conseguem fazê-lo tem contribuído para que os mestres se tornem objetos da violência de seus próprios estudantes, sobretudo por meio das práticas das agressões virtuais.

Uma das atuais formas de violência contra os professores consiste em agredi-los física e/ou verbalmente na sala de aula, filmar tais agressões e publicá-las nas redes sociais caracterizando a prática de cyberbullying. Esse tipo de violência tem crescido assustadoramente nos últimos anos conforme mostra o levantamento realizado em julho de 2019 na rede social YouTube digitando no comando de buscas o descritor "aluno agride professor". Nesse levantamento foi possível encontrar diversos vídeos que exemplificam a prática de cyberbullying contra professores, inclusive, vários deles têm como autores estudantes brasileiros. Tal levantamento, realizado com o objetivo de quantificar os vídeos que caracterizam a prática de cyberbullying contra professores, encontrou oitenta e nove vídeos que mostram docentes sendo agredidos por estudantes no Brasil. Os dados referentes ao levantamento quantitativo dos vídeos também mostraram que dos oitenta e nove vídeos encontrados, quarenta e cinco são de autoria de alunos do Ensino Fundamental, trinta e seis de estudantes do Ensino Médio e oito de estudantes universitários. Para a análise de um desses oitenta e nove vídeos encontrados, os seguintes critérios de seleção foram utilizados: 1) número de acessos registrados em relação aos vídeos publicados no YouTube; 2) número de comentários de estudantes feitos sobre esses vídeos; 3) número de comentários elaborados por professores a respeito das filmagens; 4) autoria das filmagens realizadas pelos aparelhos celulares dos próprios estudantes. Os dados coletados foram analisados por meio de categorias, tais como, desengajamento moral (BANDURA, 2015) e dessensibilização, sobretudo em relação ao modo como o desengajamento e a dessensibilização se materializam em práticas de cyberbullying de alunos contra professores na sociedade da cultura digital (TÜRCKE, 2010) Além da produção de Türcke (2010), a análise do contexto da cultura digital, no qual a indústria cultural se revitaliza, se fundamentou nas reflexões teórico-críticas elaboradas pelos pensadores da chamada Teoria Crítica da Sociedade, especialmente Adorno (1993) e Horkheimer e Adorno (1985). Já para as análises dos vídeos e comentários, além dos conceitos de Bandura (2015), foram empregados conceitos elaborados por Rocha (2010) e Zuin (2017).

$\mathrm{O}$ vídeo selecionado com duração de 2 minutos e 11 segundos tem como autor das agressões um estudante do Ensino Fundamental e foi publicado no YouTube em 2015. Tal vídeo já foi visto por 2.007.915 de pessoas tendo recebido 10 mil curtidas e 3.277 
comentários. O vídeo analisado é um recorte, ou seja, a análise considerou apenas o que está presente na filmagem. Como o vídeo gerou um grande volume de comentários, foram considerados somente aqueles em que foi possível verificar que os autores eram alunos e/ou professores. Os comentários selecionados que aparecem ao longo deste artigo foram transcritos conforme publicação original. O título do vídeo foi suprimido assim como não foi disponibilizado o link em que ele foi encontrado a fim de preservar a identidade dos sujeitos que nele aparecem. A filmagem mostra uma professora agachada apanhando alguns livros em uma estante da biblioteca. O aluno agressor está ao seu lado, em pé, e diz ao despentear a professora: "levanta capeta". Os demais alunos dão risada. Enquanto a professora continua agachada segurando um livro nas mãos ele a empurra e diz: "anda capeta!". Após ser empurrada pela segunda vez e bater a cabeça num armário, a professora desfere um tabefe em direção ao rosto do aluno que se esquiva e não é acertado. Ele a despenteia mais uma vez e grita: "para vagabunda. Olha na minha cara piranha, eu não sou da sua laia". Os alunos continuam rindo.

Logo em seguida, o aluno agressor bate nas nádegas da professora que pegava os livros em cima de uma mesa. A professora se vira para ele e indaga: "você não respeita ninguém não, rapaz?". Ele a empurra pelo braço e afirma: "você é uma bicha feia, desconfia. Você tem homem?". Neste momento, o aluno agressor bate mais uma vez nas nádegas da professora. Ela, com os livros nas mãos, questiona: "ô Fulano, você não me respeita não?". $\mathrm{O}$ aluno agressor empurra a pilha de livros que a professora estava segurando e ordena: "vai pegar, porra! Vai pegar agora! Pega!". Logo em seguida, o aluno pergunta: "você já ouviu falar em strip-tease, querida?". Ela responde: "não sou da sua laia". O aluno reage dizendo: "lógico que não. Tem que ter confiança, querida". Ainda tentando organizar os livros, a professora pede: "dá licença daqui", mas ele reage dizendo: "ai você está sentindo choque, você está tremendo, querida".

Logo após este comentário, a professora encosta no braço do aluno e pede novamente para ele se retirar. Ele diz: "opa! Você não me pariu para estar tocando em mim. E se eu pegar no seu peito, hein?". Neste momento, ele toca os seios da professora. Ela reage dando um tabefe no rosto dele. $\mathrm{O}$ aluno revida batendo no rosto da professora para, logo em seguida, gritar: "vagabunda, bate, vai!". Ela pede mais uma vez para ele se retirar da sala, mas o aluno continua a agredi-la: "bate, capeta, bate, vai!". Os demais alunos continuam rindo. $\mathrm{O}$ vídeo é então finalizado.

A agressão sofrida pela professora foi objeto de interesse de milhões de pessoas que visualizaram as imagens humilhantes sendo condenada pela maioria daqueles que assistiram ao denominado "vídeo viral" e fizeram comentários a respeito, tais como: "Coitada da professora, chega doer meu coração... o mais triste é que ninguém interferiu. Espero que essa professora continue firme e forte na luta. Que vergonha... que vídeo lamentável"; "Isso é ridiculo, no Brasil os professores sofrendo pra ganhar merreca e ainda passa por isso, serio meu to me doendo de raiva, por isso poucos hoje querem ser professor". A violência contra a professora que aparece na filmagem pode ser entendida pela discussão empreendida por Türcke (2010) sobre a perda da palpabilidade como responsável por atitudes agressivas que buscam de alguma maneira retomar a experiência 
táctil. A perda da palpabilidade está relacionada ao conceito de indústria cultural cunhado por Horkheimer e Adorno (1985) na década de 1940. Por meio do consumo de suas mercadorias, especialmente aquelas da atual indústria cultural como as tecnologias digitais, a reflexão crítica tem cedido espaço para atitudes violentas como aquelas manifestadas nas redes sociais, de tal maneira que os agressores se dessensibilizam em relação ao sofrimento das vítimas. Isso porque o fascínio causado pelas sensações audiovisuais difundidas pelas tecnologias digitais é sempre instantâneo, por isso mesmo, frustrante (TÜRCKE, 2010).

A torrente de estímulos audiovisuais, segundo Türcke (2010, p. 72), “[...] mantêm o sensacional, que tornam próximo, à distância", daí a busca constante por novas sensações que sejam ainda mais excitantes. A instantaneidade causada pelas sensações audiovisuais acaba gerando o desejo de se apoderar de algo, já que aquilo que aparece nas telas dos produtos da indústria cultural como as televisões e/ou os smartphones nem sempre permitem uma experiência formativa. Os choques audiovisuais disseminados pela indústria cultural oferecem, pois, um cotidiano pobre em experiências. Para o pensador, o que o mundo dissolvido microeletronicamente proporciona ao "[...] usuário são botões; o que exige é que os tateiem. São utilizados com delicadas pontas dos dedos, deslizando rapidamente sobre suas superfícies até escorregar para outros lugares, não tendo nunca algo que possa ser agarrado" (p. 74).

O contato diário com algo que está sempre tão próximo, na ponta dos dedos, mas que nunca pode ser realmente tocado provoca, segundo Türcke (2010), um desejo por experiências táteis, bem como o arrefecimento da consciência moral daquele e daquela que exigem fruir tais experiências. Experiências, portanto, que permitem uma realização de si por meio da construção de algo que realmente faça sentido, que possa ser de fato experimentado. Para o pensador, a compreensão sobre "[...] os atos de violência aparentemente desmotivados que se dão nas escolas e no mundo da subcultura jovem têm de ser inseridos nesse contexto mais amplo" (p. 74). Ou seja, é preciso considerar que a atual sociedade ao incitar o contato permanente com as sensações audiovisuais dificulta a realização de uma "experiência continuada de si próprio" (p. 74).

Essa experiência está relacionada ao processo de autodescobrimento pelo qual crianças e adolescentes buscam testar seus limites "[...] tanto de suas próprias forças quanto daquilo que lhes é imposto" (TÜRCKE, 2010, p. 75). Segundo o pesquisador, o rompimento das resistências táteis que são necessárias ao processo de experimentação de limites se dissolve nas condições atuais de audiovisibilidade total. Desse modo, o aluno mostrado no vídeo ao agredir verbal, física e sexualmente a professora rompe tais resistências à medida que sua dificuldade em se agarrar a uma experiência táctil, formativa e duradoura é dirigida contra o corpo da professora. Se "[...] não se é por nada verdadeiramente tocado sem ao mesmo tempo poder tomar nada nas mãos" (p. 75), então o contato que possibilitaria uma relação formativa com as pessoas e com os objetos é substituído por agarrar-se agressivamente a algo, ao mesmo tempo em que se dessensibiliza diante dos sofrimentos psicológicos e físicos de sua vítima. Ao tocar violentamente o corpo da professora mostrada no vídeo, o aluno afasta toda a possibilidade de construção de uma relação respeitosa entre eles no processo educativo. A violência praticada pelo aluno do vídeo pode ser enquadrada como 
crime de estupro conforme o Código Penal Brasileiro (Decreto-Lei n. 2.848/1940), mas também tal violência representa a perda da palpabilidade, de um "déficit de tato", para usar uma expressão de Türcke (2010). Para o pensador,

é atendo-se a algo que se sente em si próprio; agarrar até que o agarrado deixe de esboçar qualquer resistência e tenha proporcionado toda a satisfação táctil possível: na incapacidade de poder parar de bater, até que o objeto das pancadas não mais se mexa, celebra-se o triunfo do pegar, festas da certificação de si. Por ao menos um instante, sair da insensível cela de paredes forradas: Sentio, ergo sum (TÜRCKE, 2010, p. 77, grifos do autor).

Apesar de a professora agredida não ter sido espancada, de modo que seu corpo não esboçasse mais nenhum tipo de reação, ainda assim é esse mesmo corpo que se torna o objeto da humilhação e da violência do aluno exibido no vídeo. As repetidas agressões contra a professora do vídeo parecem confirmar a satisfação táctil do aluno, pois é tocando o corpo da professora repetidas vezes e sem o seu consentimento que o aluno tenta certificar-se de sua própria existência.

Para Adorno (1993, p. 30), a perda do tato representa um "[...] indício de como se tornou impossível a convivência humana nas circunstâncias atuais" como nos casos em que os indivíduos reagem com hostilidade durante o ato de cumprimentar:

[...] certa espécie de cortesia, ao invés de fazer com que se sintam tratados como seres humanos, desperta antes neles uma noção do estado desumano em que se encontram, e aquele que é cortês corre o risco de ser tomado por descortês, porque faz uso da cortesia como de um privilégio ultrapassado (ADORNO, 1993, p. 30).

O tato é, conforme o frankfurtiano, um dos sentidos que humaniza mulheres e homens ao possibilitar a relação humana por meio do con-tato com os outros. Assim, a perda do tato, para Adorno (1993), significa o embrutecimento, a dessensibilização e a desumanização. $\mathrm{Na}$ atual sociedade, a hostilidade ao tato, denunciada pelo frankfurtiano em meados do século 20, pode ser atualmente revitalizada pelo prazer proporcionado pelas conversas nas redes sociais ao invés do diálogo face a face; pelos encontros amorosos em sites de relacionamento que adiam uma possível rejeição, mas que também mutilam a possibilidade de realmente ter con-tato com alguém; pela possibilidade de se despedir de um ente querido ao acompanhar ao vivo a transmissão online de seu velório ao invés de viver o luto como um momento de elaboração do sofrimento em con-tato com familiares e amigos. A hostilidade ao tato é a hostilidade ao contato humano. É a hostilidade em relação ao outro e a si próprio; é o embrutecimento.

Para Arendt (2012, p. 627), a existência humana depende das relações interpessoais, pois "para a confirmação da minha identidade, dependo inteiramente de outras pessoas". Todavia, na era da audiovisibilidade total, a vida como experiência formativa vai sendo substituída pela existência por meio das tecnologias digitais mediante o distanciamento em 
relação ao contato com o outro. Desse modo, o aluno agressor do vídeo ao agarrar violentamente a própria professora manifesta a perda do tato expondo a dificuldade de se relacionar de fato com algo e/ou com alguém. Nesses termos, a satisfação táctil provocada pelo contato com o corpo da professora mostrada no vídeo além de evidenciar a perda da palpabilidade na atual sociedade endossa aquilo que a educação, segundo Adorno (1995), deveria combater, a saber, os traços sociais de barbárie.

A crueldade de alguns comentários corrobora a barbárie denunciada por Adorno (1995) que deveria ser objeto de atenção da educação, como estes: "Nessas horas precisamos de um Funher como Adolf Hittler nesse Brasil para colocar ordem nessa Merda"; "Olha eu já vi cara xingando a professora mas fazer o que esse cara fez pode dar o título do Óscar pra ele que ele merece!"; "Mas a professora é bonita e gostosa aí o menino não consegue segurar"; "Ela tabem tava gostando .....pq se fosse outra tinha dado uma surra nele". Os comentários confirmam a compreensão percebida por Adorno (1995) de que as condições históricas e sociais que engendraram os regimes totalitários não desapareceram por completo, por isso, a necessidade de a educação não repetir a barbárie perpetrada pelo fascismo. O pensador acreditou na formação cultural como capaz de promover uma consciência verdadeira que se colocasse contra o pensamento totalitário. A formação cultural entendida por Adorno (2010) diz respeito a aquele tipo de formação que é capaz de educar integralmente o indivíduo em termos culturais, filosóficos, éticos, estéticos e políticos. O indivíduo formado culturalmente é capaz de repensar sua forma de agir revendo, por exemplo, seus preconceitos com a intenção de provocar uma mudança ética em seu comportamento.

Os comentários agressivos direcionados contra a professora mostrada no vídeo corroboram a necessidade da presença de espectadores para a prática de cyberbullying como apontou Rocha (2010) e podem ser analisados também sob a ótica do desengajamento moral discutido por Bandura (2015). No caso dos autores dos comentários eles deslocam sua responsabilidade pela ação danosa para o aluno agressor que aparece no vídeo considerando-o como o único responsável pela violência à professora. Ao agirem dessa forma os comentários podem ser violentamente escritos, pois o deslocamento da responsabilidade "[...] opera ao obscurecer ou minimizar o papel de agente no dano que a pessoa pode causar. [...] Por não ser o real agente de suas ações, ela se poupa de reações autocondenatórias" (BANDURA, 2015, p. 29).

Além do deslocamento da responsabilidade, Bandura (2015) também destaca a difusão de responsabilidade como mecanismo do desengajamento moral ao explicar que "o exercício do controle moral também é enfraquecido quando a agência pessoal é obscurecida pela difusão da responsabilidade pelo comportamento nocivo" (p. 33). Os comentadores que visualizaram o vídeo se sentem motivados a agredir verbalmente a professora ao encontrar colegas que procedem da mesma forma. Assim, ao perceberem que os outros estudantes também estão agredindo a professora, eles deslocam a responsabilidade de seus atos agressivos para todo o grupo que promoveu a agressão. Os estudantes que postaram comentários agressivos à professora percebem, portanto, que quando um grupo se junta para praticar atos violentos a responsabilidade é espraiada também no ambiente virtual, o 
que fomenta o sentimento de que ninguém pode ser de fato responsabilizado, pois “"[...] as pessoas agem mais cruelmente sob a responsabilidade do grupo do que quando elas se julgam pessoalmente responsáveis por suas ações” (BANDURA, 2015, p. 33).

Nesse contexto, a violência contra professores, praticada por seus próprios alunos e endossada por comentários de outros estudantes que se desengajam moralmente apoiados pelos usos das tecnologias digitais da indústria cultural, revitaliza ainda mais o papel da educação de contribuir para desbarbarizar os sujeitos no processo educativo. A agressão praticada por alunos contra professores sob a forma de cyberbullying solapa, desse modo, a possibilidade de "[...] diferenciar e tornar mais delicadas as pessoas no processo educacional" (ADORNO, 1995, p. 168). O processo de desbarbarização que consiste na formação do pensamento crítico e na construção da sensibilidade humana passa, como acreditou o frankfurtiano, necessariamente pelo exercício da autoridade docente responsável por possibilitar a elaboração de uma relação respeitosa e afetuosa quanto ao processo educativo.

\section{Considerações finais}

Os conceitos e a discussão sobre o bullying escolar e o cyberbullying contra professores têm contribuído para a compreensão do modo como esses fenômenos se atualizam na era das tecnologias digitais da indústria cultural. Se, de um lado, tais tecnologias são pensadas e utilizadas para fomentar experiências formativas entre professores e alunos contribuindo para que eles estejam efetivamente em contato no processo educativo. Por outro lado, essas mesmas tecnologias têm viabilizado a prática de agressões virtuais contra professores que acontecem pelas filmagens, pela criação de comentários ofensivos e pelo compartilhamento das imagens humilhantes dos mestres nas redes sociais.

A violência sob a forma de cyberbullying mostra que a necessidade de educar contra a barbárie continua sendo tarefa fundamental da educação, pois como escreveu Adorno (1995, p. 156), "[...] a tentativa de superar a barbárie é decisiva para a sobrevivência da humanidade". O processo de luta contra a barbárie está relacionado à formação cultural e à construção de uma sociedade de pessoas emancipadas, já que "a formação é tida como condição implícita a uma sociedade autônoma: quanto mais lúcido o singular, mais lúcido o todo" (ADORNO, 2010, p. 13).

Os crescentes casos de agressões virtuais contra professores nas redes sociais endossam a necessidade da formação cultural ao mesmo tempo que revelam como as tecnologias digitais da indústria cultural podem distanciar os indivíduos da experiência táctil, duradoura e formativa com algo e/ou alguém que é tão necessária ao processo de sensibilização humana e de construção do esclarecimento. A perda da palpabilidade discutida por Türcke (2010), ou seja, a incapacidade de se relacionar com aquilo com que se entra em contato, distancia professores e alunos solapando a possibilidade de construção de uma relação pedagógica mais humana no processo educativo. No que concerne à 
realidade educacional de nosso país, notadamente caracterizada por se fundamentar em condições infraestruturais muitas vezes precárias, desde salários aviltantes de professores a ineptos laboratórios, redes de informática e bibliotecas, esta perda da palpabilidade, destacada por Türcke (2010), pode estimular ainda mais o distanciamento entre professores e alunos, haja vista a debilidade de vínculos entre tais agentes educacionais decorrente dos problemas infraestruturais anteriormente enfatizados.

Esse distanciamento contribui para que a autoridade docente seja cada vez mais questionada pelos estudantes fazendo com que estes, ao dominarem os usos das tecnologias digitais da indústria cultural, controlem também a publicação das imagens humilhantes de seus mestres nas redes sociais. Sendo assim, ao disseminarem cotidianamente os estímulos audiovisuais que chegam aos consumidores da indústria cultural, especialmente pelas telas de seus smartphones, aparelhos que possibilitam a criação e o compartilhamento das imagens dos professores sendo agredidos, tais estímulos não cessam de oferecer um cotidiano pobre em experiências, por isso mesmo, farto de atos violentos.

A compreensão crítica sobre as agressões virtuais contra professores realizadas por seus próprios alunos ensina que as relações entre tais sujeitos podem ser transformadas pelo con-tato com a formação cultural que, mediada pela autoridade docente, é capaz de educar para a sensibilidade e para a autonomia. Esse con-tato entre professores e alunos pode ser proporcionado também pelas tecnologias digitais da indústria cultural desde que sejam utilizadas visando o processo de construção do conhecimento que acontece mediante o exercício da autoridade docente com vistas a promover o combate à hostilidade e ao embrutecimento no cotidiano da prática educativa. A violência contra professores na forma de cyberbullying precisa, pois, ser discutida nas instituições de ensino, haja vista a necessidade de que mestres e alunos se sensibilizem no processo educativo pelo con-tato entre si e com o conhecimento para que a educação não seja conivente com a barbárie.

\section{Referências}

ADORNO, Theodor Wiesengrund. Televisão, consciência e indústria cultural. In: COHN, Gabriel (Org.). Comunicação e indústria cultural. 4. ed. São Paulo: Editora Nacional, 1978. p. 346-354.

ADORNO, Theodor Wiesengrund. Minima moralia: reflexões a partir da vida danificada. Trad. Luis Eduardo Bicca. 2. ed. São Paulo: Editora Ática, 1993. 216p.

ADORNO, Theodor Wiesengrund. Educação e emancipação. 4. ed. Trad. Wolfgang Leo Maar. Rio de Janeiro: Paz e Terra, 1995. 190p.

ADORNO, Theodor Wiesengrund. Teoria da semiformação. In: PUCCI, Bruno; ZUIN, Antonio Álvaro Soares; LASTÓRIA, Luiz Antonio Calmon Nabuco (Orgs.). Teoria crítica e inconformismo: novas perspectivas de pesquisa. Campinas: Autores Associados, 2010. p. 07-40.

ALMEIDA, Rafael José de Alencar. Estudo da ocorrência de cyberbullying contra professores na rede social Twitter por meio de um algoritmo de classificação bayesiano. Texto livre: linguagem e tecnologia. Belo 
Horizonte, v. 5, n. 1, p.77-83, jan./jun. 2012. Disponível em: http://www.periodicos.letras.ufmg.br/ index.php/textolivre/article/view/1809/7264 Acesso em: 13 abr. 2020.

ANTUNES, Deborah Christina. Bullying: razão instrumental e preconceito. São Paulo: Casa do Psicólogo, 2010. 243p.

ARENDT, Hannah. Totalitarismo. In: ARENDT, Hannah. Origens do totalitarismo. Coleção Companhia de Bolso. Trad. Roberto Raposo. São Paulo: Companhia das Letras, 2012. p. 415-629.

BANDURA, Albert. Desengajamento moral na perpetração de desumanidades. Trad. Ana Cecília de Medeiros Maciel. In: BANDURA, Albert; AZZI, Roberta Gurgel; TOGNETTA, Luciene Regina Paulino (Orgs.). Desengajamento moral: teoria e pesquisa a partir da Teoria Social Cognitiva. Campinas: Mercado de Letras, 2015. p. 19-64.

BOURDIEU, Pierre; PASSERON, Jean-Claude. Fundamentos de uma teoria da violência simbólica. In: BOURDIEU, Pierre; PASSERON, Jean-Claude. A reprodução: elementos para uma teoria do sistema de ensino. 3.ed. Trad. Reynaldo Bairão. Rio de Janeiro: Editora Francisco Alves, 1992. p. 15-75.

BRASIL. Decreto-Lei n. 2.848, de 7 de dezembro de 1940. Código Penal. Brasília, DF; Presidência da República [1940]. Disponível em: http://www.planalto.gov.br/ccivil_03/decretolei/del2848compilado.htm Acesso em: 15 abr. 2020.

BRASIL. Lei n. 12.737, de 30 de novembro de 2012. Dispõe sobre a tipificação criminal de delitos informáticos; altera o Decreto-Lei $\mathrm{n}^{\circ} 2.848$, de 7 de dezembro de 1940 - Código Penal; e dá outras providências. Brasília, DF: Presidência da República, [2012]. Disponível em: http://www.planalto.gov.br/ccivil_03/_Ato2011-2014/2012/Lei/L12737.htm Acesso em: 13 abr. 2020.

BRASIL. Lei $n^{\circ}$ 13.185, de 06 de novembro de 2015. Institui o Programa de Combate à Intimidação Sistemática (Bullying). Brasília, DF: Presidência da República, [2015]. Disponível em: http://www.planalto.gov.br/ccivil_03/_Ato2015-2018/2015/Lei/L13185.htm Acesso em: 13 abr. 2020.

BAUMAN, Sheri; TOOMEY, Russell B.; WALKER, Jenny L. Associations among bullying, cyberbullying and suicide in high school students. Journal of adolescence, 36, 341-350, 2013.

CANAVEZ, Fernanda. A escola na contemporaneidade: uma análise crítica do bullying. Psicol. Esc. Educ., Maringá, v. 19, n. 2, p. 271-278, ago. 2015. Disponível em: http://www.scielo.br/scielo.php?script=sci_ arttext\&pid=S1413-85572015000200271\&lng=en\&nrm=iso Acesso em: 01 out. 2020.

CHARLOT, Bernard. A violência na escola: como os sociólogos franceses abordam essa questão. Sociologias. Porto Alegre, ano 4, n. 8, p. 432-443, jul./dez. 2002. Disponível em: http://www.scielo.br/pdf/soc/n8/n8a16.pdf Acesso em: 06 abr. 2020.

CONTE, Christiany Pegorari; ROSSINI, Augusto Eduardo de Souza. Aspectos jurídicos do cyberbullying. Revista FMU Direito. São Paulo, v. 24, n. 34, p. 46-65, jul./dez. 2010. Disponível em: http://www.revistaseletronicas.fmu.br/index.php/FMUD/article/view/94/91 Acesso em: 14 abr. 2020.

FOUCAULT, Michel. Vigiar e Punir: nascimento da prisão. 38. ed. Trad. Raquel Ramalhete. Petrópolis: Vozes, 2010. 291p.

FREUD, Sigmund. Algumas reflexões sobre a psicologia escolar. In: FREUD, Sigmund. Obras psicológicas completas de Sigmund Freud, vol. XIII. Rio de Janeiro: Imago, 1969. p. 283-288.

HORKHEIMER, Max; ADORNO, Theodor Wiesengrund. Dialética do esclarecimento: fragmentos filosóficos. Trad. Guido Antonio de Almeida. Rio de Janeiro: Jorge Zahar Editora, 1985. 254p.

HINDUJA, Sameer; PATCHIN, Justin W. Bullying, cyberbullying, and suicide. Arquives of Suicide Research, 14, 206-221, 2010.

KYRIACOU, Chris. Helping Troubled Pupils. Cheltenham: Nelson Thornes, 2003. 152p.

NIETZSCHE, F. Assim falou Zaratustra: um livro para todos e para ninguém. Trad. Mário da Silva. 9a ed. Rio de Janeiro: Civilização Brasileira, 2005. 381p. 
OLWEUS, Dan. Bullying at school: what we know and what we can do. United Kingdom: Blackwell publishing, 1993. 152p.

O'HIGGINS, James Norman.; CONNOLY, Justin. Mimetic theory and scapegoating on the age of cyberbullying: the case of Phoebe Prince. Pastoral Care in Education, 29 (4), 287-300, 2011.

PRADOS, Maria Ángeles Hernández; FERNÁNDEZ, Isabel Maria Solano. Cyberbullying, un problema de acoso escolar. Revista Iberoamericana de la Educación Digital. Madrid/España, v. 10, n. 1, p. 17-36, 2007. Disponível em: https://docs.google.com/viewerng/viewer?url=http://revistas.uned.es/index.php/ ried/article/viewFile/1011/927 Acesso em: 14 abr. 2020.

ROCHA, Telma Brito. Scraps de ódio no orkut: cyberbullying, contextos e ressonâncias da violência virtual que atinge o professor. Orientador: Roberto Sidnei Macedo. 2010. 211f. Tese (Doutorado em Educação) Faculdade de Educação, UFBA, Salvador, 2010.

SANTOS, José Vicente Tavares dos. A violência na escola: conflitualidade social e ações civilizatórias. Educação e Pesquisa. São Paulo, v. 27, n. 1, p. 105-122, jan./jun. 2001. Disponível em: http://www.scielo.br/scielo.php?script=sci_arttext\&pid=S1517-97022001000100008\&lng=en\&nrm=iso Acesso em: 01 out. 2020.

SILVA, Ana Beatriz Barbosa. Bullying: mentes perigosas nas escolas. Rio de Janeiro: Objetiva, 2010. 188p.

SMITH, Peter K. Intimidação por colegas e maneiras de evitá-la. In: DEBARBIEUX, Eric; BLAYA, Catherine (Orgs.). Violência nas escolas e políticas públicas. Brasília; UNESCO, 2002. p. 187-205.

STELKO-PEREIRA, Ana Carina; WILLIAMS, Lúcia Cavalcanti de Albuquerque. Reflexões sobre o conceito de violência escolar e a busca por uma definição abrangente. Temas em Psicologia. Ribeirão Preto, v. 18, n. 1 , p. 45-55, dez./2010. Disponível em: http://pepsic.bvsalud.org/scielo.php?script=sci_ arttext\&pid=S1413-389X2010000100005\&lng=pt\&nrm=iso Acesso em: 06 abr. 2020.

TOGNETTA, Luciene Regina Paulino; BOZZA, Thais Cristina Leite. Cyberbullying: quando a violência é virtual - Um estudo sobre a incidência e sua relação com as representações de si em adolescentes. In: GUIMARÃES, Áurea Maria; ZAN, Dirce Djanira Pacheco e (Orgs.). Anais do I Seminário Violar: problematizando juventudes na contemporaneidade. Campinas: UNICAMP, 2010. p. 839-857.

TOGNETTA, Luciene Regina Paulino; ROSÁRIO, Pedro. Bullying: dimensões psicológicas no desenvolvimento moral. Estudos em Avaliação Educacional. São Paulo, v. 24, n. 56, p. 106-137, set./dez. 2013. Disponível em: http://www.fcc.org.br/pesquisa/publicacoes/eae/arquivos/1869/1869.pdf Acesso em: 12 abr. 2020.

TÜRCKE, Christoph. Sociedade excitada: filosofia da sensação. Trad. Antônio A. S. Zuin [et al.]. Campinas: Editora da Unicamp, 2010. 323p.

ZUIN, Antonio Álvaro Soares. Adoro odiar meu professor: o aluno entre a ironia e o sarcasmo pedagógico. Campinas: Autores Associados, 2008. 118p.

ZUIN, Antonio Álvaro Soares. Cyberbullying contra professores: dilemas da autoridade dos educadores na era da concentração dispersa. São Paulo: Edições Loyola, 2017. 166p.

\section{Correspondência}

Camila Sandim de Castro: Doutora em Educação pela Universidade Federal de São Carlos, Mestra em Educação pela Universidade Federal de Lavras e Licenciada em Educação Física pela Universidade Federal de Lavras. Professora da Rede Municipal de Ensino de Barroso, Minas Gerais, Brasil. Membro do Grupo de Estudos e Pesquisas "Teoria Crítica e Educação".

E-mail: camilasandim23@gmail.com 
Antonio Álvaro Soares Zuin: Pós-Doutor em Filosofia da Educação pela Universidade de Leipzig/Alemanha, Pós-Doutor em Psicologia da Educação pela Universidade de York/Inglaterra, PósDoutor em Sociologia da Educação pela Universidade Johann Wolfgang von Goethe/Alemanha. Doutor em Educação pela Universidade Estadual de Campinas. Professor Titular do Departamento de Educação e do Programa de Pós-Graduação da Universidade Federal de São Carlos (UFSCar/Campus São Carlos). Coordenador do Grupo de Estudos e Pesquisas “Teoria Crítica e Educação”.

E-mail: dazu@ufscar.br

Texto publicado em Currículo sem Fronteiras com autorização dos autores 